\title{
The use of numerical modelling to determine the stress within \\ early age cemented paste used to backfill an underground stope
}

\author{
RL Veenstra AMC Consultants Pty Ltd, Australia \\ MW Grabinsky University of Toronto, Canada \\ WF Bawden Mine Design Engineering, Canada \\ BD Thompson Mine Design Engineering, Canada
}

\begin{abstract}
The determination of the in situ pressures within a backfilled stope is important for mines looking to move from a plug pour filling strategy to a continuous pouring strategy. This paper presents a methodology developed for the numerical modelling of these pressures.

This paper presents the model design criteria, approach methodology, and the input parameters required. Included in the input parameter discussion is a description of the laboratory methods used for determining the input parameters.
\end{abstract}

The results from the modelling of two case study stopes are presented and these results are compared to in situ instrumentation installed in these test stopes.

\section{$1 \quad$ Introduction}

Cemented paste backfill (CPB) has become an increasingly popular method for backfilling underground stopes for a variety of reasons, including its engineered design, relative ease and speed of transfer, and the ability to reduce the amount of surface area required for waste storage. While work has been done to understand the late curing age behaviour, there is less understanding of how CPB behaves during early curing times. A better understanding of the behaviour of paste during this period would increase the cost savings for mining operations.

An example of this would be the reduction of plug pours. These pours, a hold-over from the use of hydraulic fill, were used to protect the barricade by creating a shear plug between the barricade and the main body of the stope. This was accomplished by pouring CPB up to a height of a few metres above the brow and letting it cure for 3-7 days. After this curing had taken place, the rest of the stope would be poured. However, if it was possible to pour the stope continuously and eliminate the curing stage, there would be a decrease in stope cycle time and possible savings associated with that.

However, before continuous pours can be achieved, two uncertainties need to be addressed. The first is how much load can the backfill barricade take, and the second is how much load will the backfill place on the barricade. These stresses are dictated by a range of parameters including: binder content, binder type, tailings type, additional aggregates, filling rate, stope geometry, etc.

In order to examine this problem the authors have developed a numerical code based within Itasca's FLAC3D (Itasca Consulting Group, Inc. [Itasca] 2009). This model, combined with in situ stress measurements obtained from a series of test stopes, allowed a more nuanced understanding of how the stresses within the stope could be modelled. These stopes were instrumented as part of a field project 
undertaken by the University of Toronto. As part of this project, there were several test stopes at three mine sites, two in Northern Ontario and one in Turkey (Thompson et al. 2011).

This paper presents the procedure developed by the authors for modelling the stress development within the CPB during the filling of an underground stope. It will take the reader through the design methodology of the model and present a list of required material properties. The laboratory testing program, undertaken to provide these required properties, and its result will be presented and discussed. Finally, two case studies will be presented comparing the model results with that of actual in situ instrumentation discussed above.

\section{$2 \quad$ Designing the model}

In order to develop the model four criteria were defined: the model must have the ability to:

- Use a variable rise rate, including the possibility of no rise rate.

- Use time-dependent input parameters.

- Use both 2D and 3D geometries, as well as be able to account for the complex shape of most stopes.

- Use two or more different materials within the stope as it is common practice to use multiple paste recipes within the same stope even when performing a continuous pour.

The first two criteria highlight that CPB has two time scales that need to be dealt with. The first time scale is the pour time or the time it takes to fill the stope. This can range from a few days to, depending on plant or reticulation mishaps, several weeks. The second time scale is the curing age of the paste. As cement is a vital part of $\mathrm{CPB}$, its behaviour will change as the cement starts to hydrate. This means that these material properties are time-dependant.

In order to take into account both time scales, a layered modelling approach was taken with a stope being divided into a series of layers. The height of these layers was dependent mainly on the fill rate of the stope during the pour. Typically models are broken into zones which are the building blocks of the model. In the case of all the models shown in this paper, these models were divided into uniform cubes. However, there is a practical limit to the number of zones in the model as there is a trade-off between minimal zone size, appropriate layer thicknesses for numerical modelling, and model run times. A small zone size means longer run times. It was typically found that a zone size based on the minimal hourly filling rate in the stope resulted in both acceptable zone sizes and run times. Note that this means that a stope with different fill rates would have a series of thick and thin layers.

This staging process incorporated the pour time into the model. However, it had the added benefit of also being able to incorporate the curing age of the CPB into the model as well. Figure 1 shows a schematic of how this was achieved.
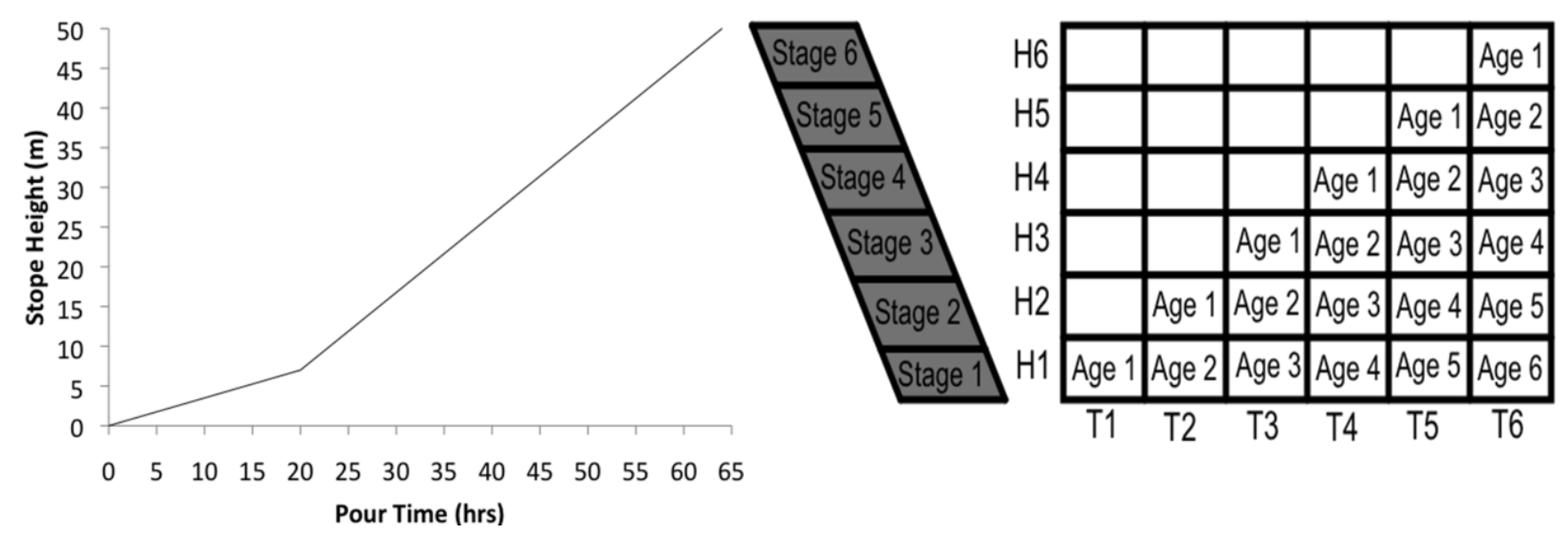

Figure 1 Schematic of pour time and curing age methodology 
The graph on the right shows the filling rate of the stope. It has a slower fill rate at the beginning and a faster filling rate at the end. The image in the middle is the stope divided into six stages. When the stope first starts to fill only Stage 1 is placed and it is given the material properties of the first curing age. After the model is run for the first stage, Stage 2 is added. Stage 2 is now given the properties of the first curing age, Stage 1 is given the parameters of the second curing age, and the model is run again. This procedure is carried out for each stage until the stope is filled.

In order to incorporate the third criteria, the chosen model code needed to be able to model both 2D and 3D problems. The model code used was Itasca's FLAC3D software package (Itasca 2009). There are multiple reasons for this choice; however, the three main reasons why it was chosen are explained in further detail below. The first reason for this was that it was a 3D code. To be able to model in 3D was important as stope geometries are not uniform 3D shapes. This is shown in Figure 2 which presents three stope surface geometries generated from cavity monitoring surveys (CMS).

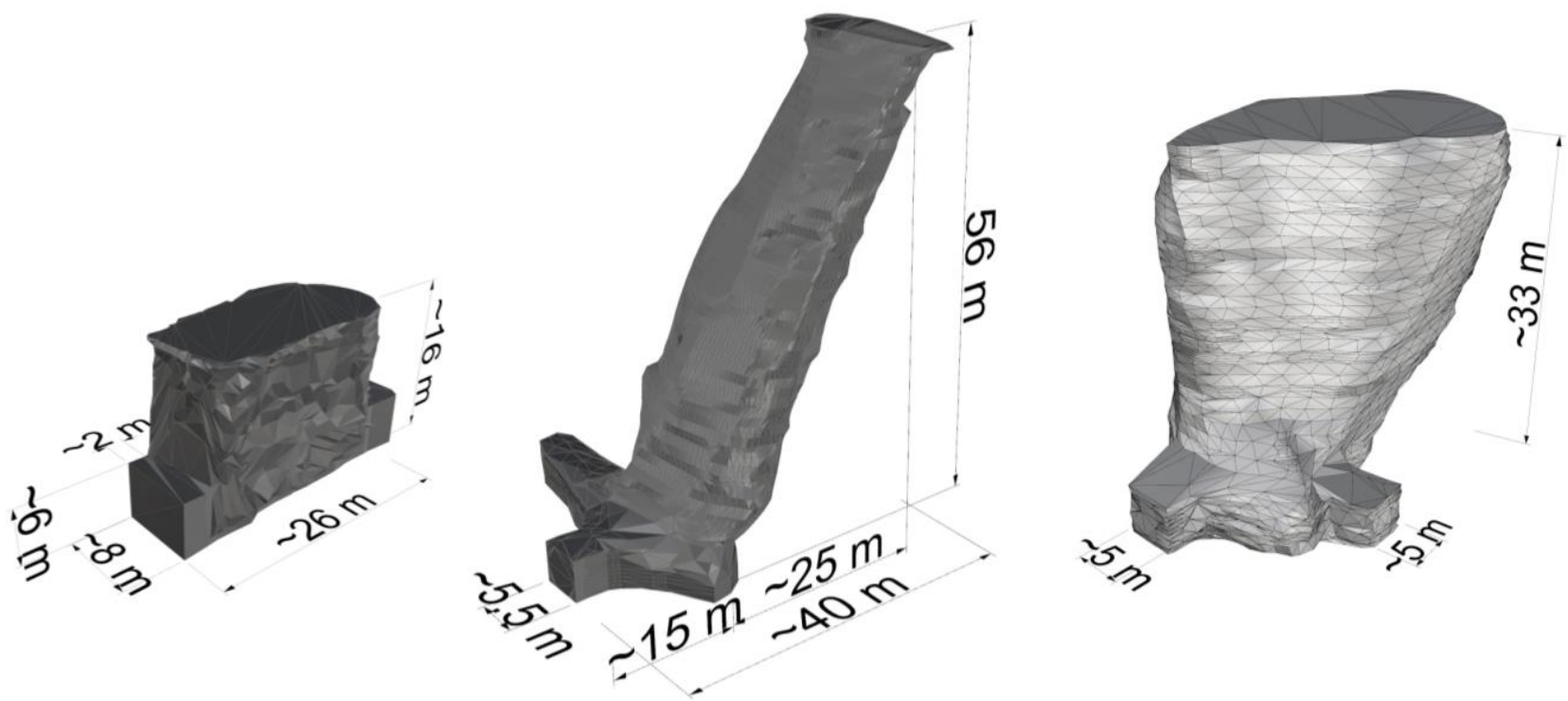

Figure 2 Cavity monitoring surveys for three stopes

Each stope has a very different shape. The first is a relatively short rectangular-shaped stope. The second stope is from a tabular, steeply dipping orebody and the CMS shows that the drift access and undercut of the stope have complex shapes. It would be difficult to represent this stope in $2 \mathrm{D}$ and be able to model the area of most interest, namely, the area closest to the barricade. The third surface shows another dipping stope but one with a much larger volume and irregular shape. This irregular shape, and the additional feature of having two drift access points, makes this stope impossible to model in two dimensions.

In order to create the necessary 3D model meshes, the CMS surfaces were used. Once these were created it was possible to create 2D meshes by deleting the unrequired zones. An example of these meshes is shown in Figure 3, with the rock 'mould' shown in black and the paste shown in grey. 


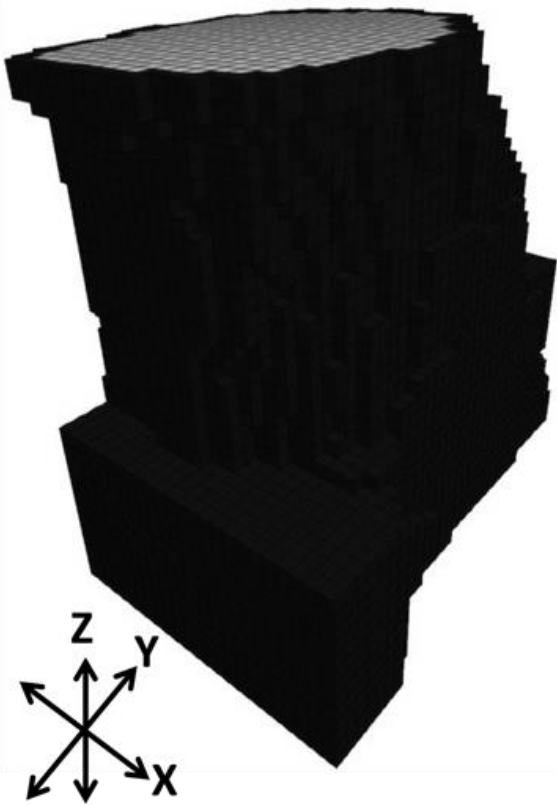

(a)

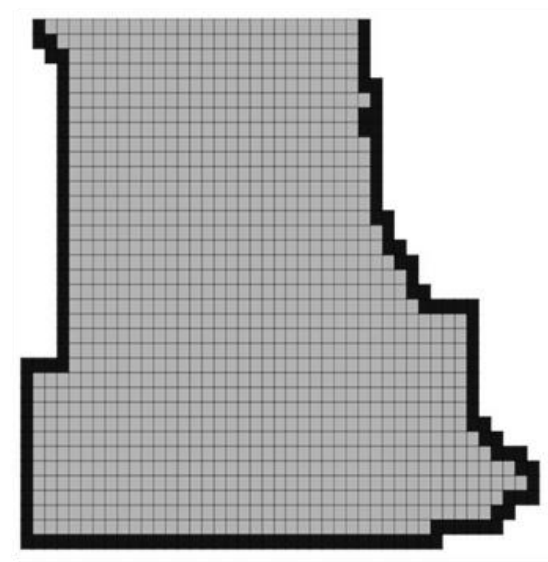

(b)

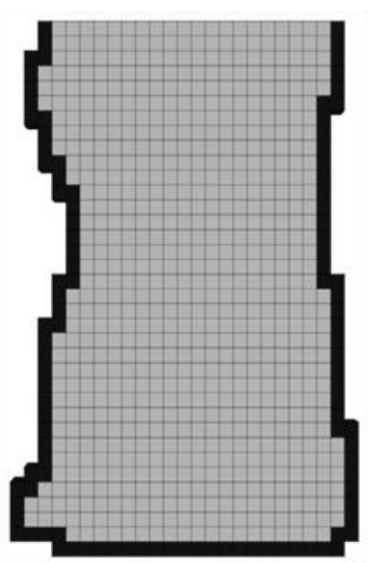

(c)

Figure 3 Generated meshes in (a) $3 \mathrm{D}$; (b) 2D along y-axis; and (c) 2D along $x$-axis

The second reason why FLAC3D was chosen was its internal programming language, FISH. This language allowed the first, second, and fourth criteria to be implemented in the model. The third reason for using FLAC3D is that it allows for non-linear material behaviour. It also has the additional benefit of being able to model fully-coupled fluid flow.

\section{Determination of input parameters}

The model was run as a fully-coupled isotropic fluid model using the Mohr-Coulomb failure criterion to model the behaviour of the paste. This meant that the model required the input of six time-dependent input parameters: the filling rate of the stope, the bulk and shear moduli ( $K$ and $G$ ), and the hydraulic conductivity or permeability $(k)$, cohesion $(c)$, and friction angle $(\phi)$ for any of the pastes being used in the model. The filling rate of the stope was determined by using a mine's paste production rate and the volume of the stope, and by examining the in situ instrumentation from the stope being modelled. The rest of the parameters were determined from a laboratory testing program.

\subsection{Laboratory testing}

The testing apparatus used in the lab was a direct shear box and was used because the tests were relatively quick test to perform, relatively easy to interpret, could generated most of the required parameters, and is a common type of testing. Figure 4 features three photographs showing a shear box test before, during, and after the test. 


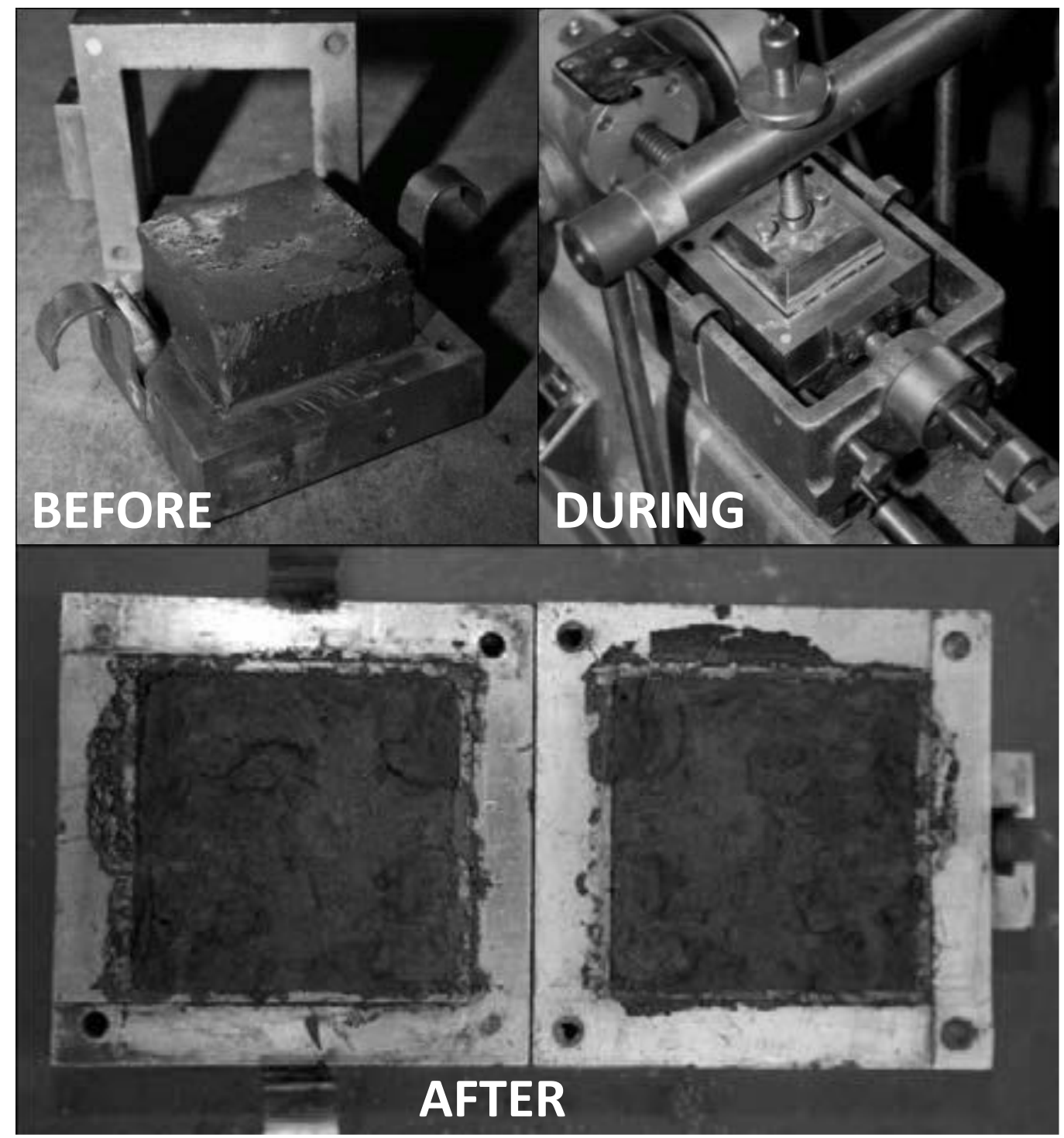

Figure 4 Photographs showing the shear box sample before testing, during testing, and after testing

There were six main testing ages; four, 12, 24, 48, 96, and 168 hours (one week). The testing was conducted at four normal stresses; 50, 100, 250, and $400 \mathrm{kPa}$. This upper value was chosen as it was close to the higher range of observed stresses recorded in any of the test stopes. Each test consisted of two components; consolidation and shearing.

\subsubsection{Consolidation testing}

At the start of each test the sample was subjected to incremental normal loading. Before the next incremental load was applied, the sample was allowed to consolidate. As the shear box was equipped with both vertical and horizontal linear displacement transducers (LDTs), the vertical displacement with time was known. These plots were used, in a similar way to an oedometer test, to determine consolidation parameters of the paste, such as coefficient of consolidation $\left(C_{v}\right)$, coefficient of volume compressibility $\left(m_{v}\right)$, compression index $\left(C_{c}\right)$, and recompression index $\left(C_{r}\right)$. 
The stiffness moduli $\left(K\right.$ and $G$ ) were determined using the relationship between $m_{v}$ and $M$, the constrained stiffness modulus. This relationship is defined below:

$$
M=\frac{4}{3} K+G=\frac{1}{m_{v}}
$$

Where:

$$
\begin{aligned}
& M \quad=\text { constrained modulus. } \\
& K \quad=\text { bulk modulus. } \\
& G \quad=\text { shear modulus. } \\
& m_{v} \quad=\text { coefficient of volume compressibility. }
\end{aligned}
$$

It should be noted that Poisson's ratio $(v)$ is required in order to determine the stiffness. The cement industry has long linked Poisson's ratio to the cement maturity or the degree of hydration (Boumiz et al. 1996; Galaa et al. 2012). This relationship typically has the initial ratio of 0.5 for fresh cement. The ratio then decreased to around 0.25-0.2 after approximately 24 hours. A similar curve was used in the models presented in this paper. Figure 5 shows an example of a $m_{\vee}$ curve obtained during the testing, as well as an estimated $v$ curve.

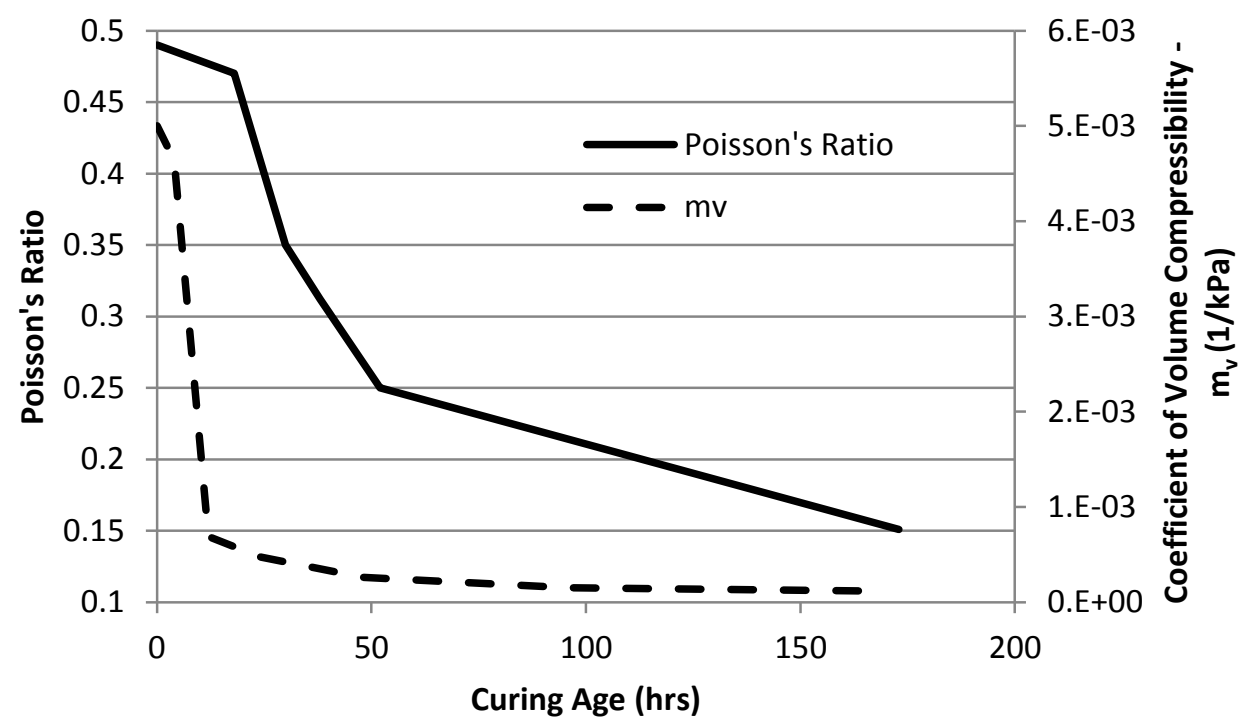

Figure 5 Example of Poisson's ratio and coefficient of volume compressibility $\left(m_{v}\right)$ curves with curing age

The permeability was calculated using the following equation:

$$
k=C_{v} m_{v} \gamma_{w}
$$

Where:

$$
\begin{aligned}
& k=\text { the hydraulic conductivity or permeability. } \\
& \gamma_{w}=\text { the unit weight of water. } \\
& m_{v}=\text { the coefficient of volume compressibility. } \\
& c_{v}=\text { the coefficient of consolidation. }
\end{aligned}
$$

\subsubsection{Shear testing}

Once the samples were loaded to the appropriate normal stress and consolidation had finished taking place, the sample was sheared. The shear box apparatus used could move in both directions so each sample was sheared until both the residual and peak shear stresses were determined. This allowed the 
peak cohesion and friction angle values to be determined. Figure 6 shows the change in both the cohesion and friction angle results for six CPB recipes over the first 200 hours of curing, as derived from the testing.

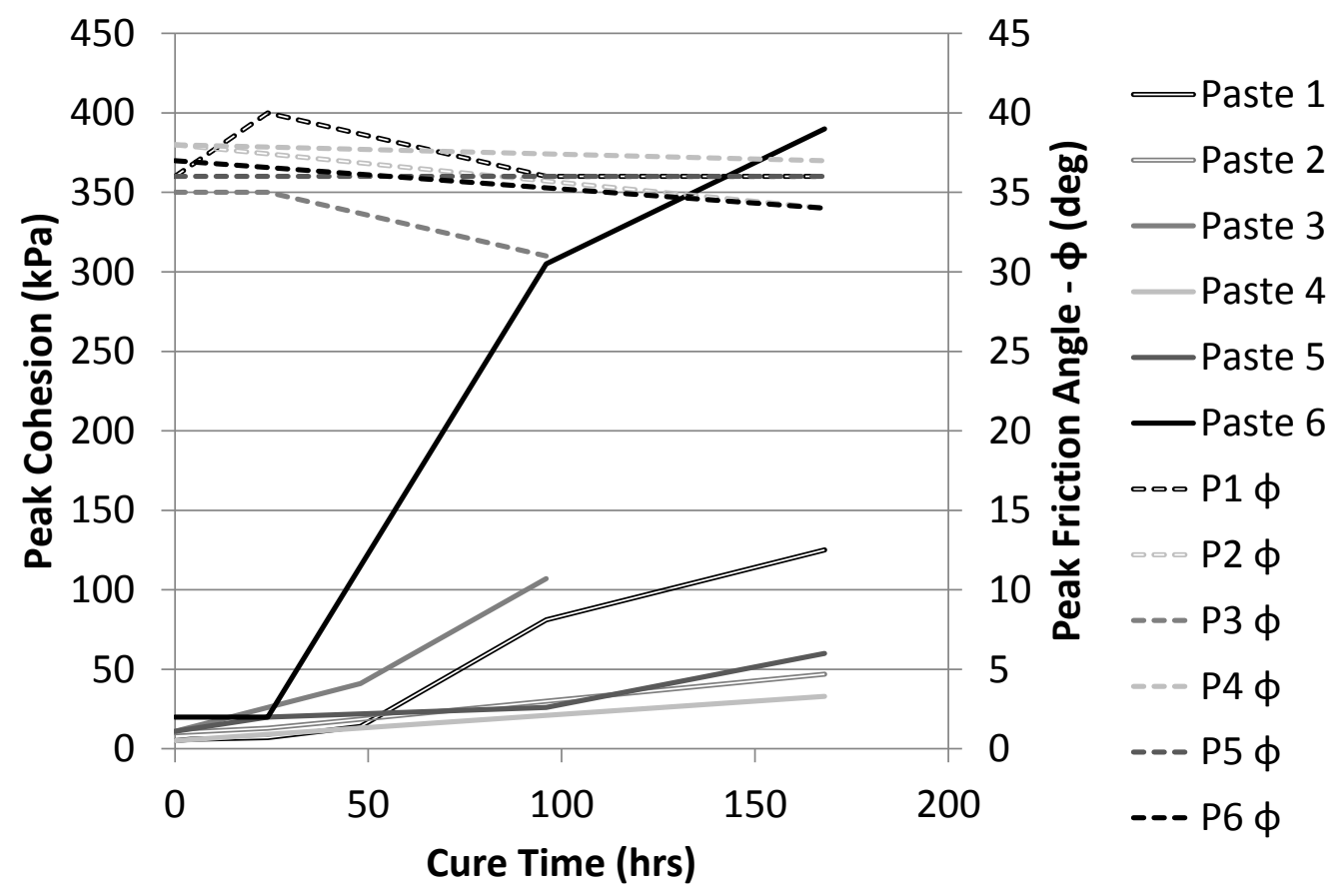

Figure 6 Peak cohesion and shear derived from direct shear box testing

All of the friction angle curves show the same trend with a general decay with time. All of the cohesion curves show a general increase over time but there is a marked difference between the magnitude of the cohesion gain and the period of time over which the increase takes place.

\subsection{Boundary conditions}

Three main boundary conditions were placed on the model. The first was that the rock mould, as described in Section 2 and shown in Figure 3, was fixed in all directions. The purpose of this mould was to provide a vessel for the paste to be placed into. The second was that no interface style elements were placed between the paste and the rock. The main assumption behind this was that any shearing would take place inside the paste as opposed to the rock-paste interface. The third boundary condition was that the rock-paste interface had a pore water pressure equal to zero. This is obviously not the case in a real stope but is a reasonable starting assumption as the rock mass is generally accepted to be more permeable than the paste.

\section{$4 \quad$ Case studies}

The following section will present the results from two different test stopes. These stopes will be presented in more detail later in this section but first a brief description of the instrumentation placed in the stopes will be discussed.

\subsection{Stope instrumentation}

In terms of this paper, the instrumentation cluster configuration depended on where it was installed in the stope. In the main body of the stope and in access drifts the instrument cluster consisted of a wire cage containing three total earth pressure cells (TEPCS) and a piezometer (PZ). The three TEPCs were installed in the three orthogonal directions $(x, y$, and $z)$. A photograph of a cage is shown in Figure $7(a)$. The barricade instrumentation also included a TEPC and a PZ, which were directly installed onto the barricade together at various heights. Figure $7(b)$ shows an example of this installation. 


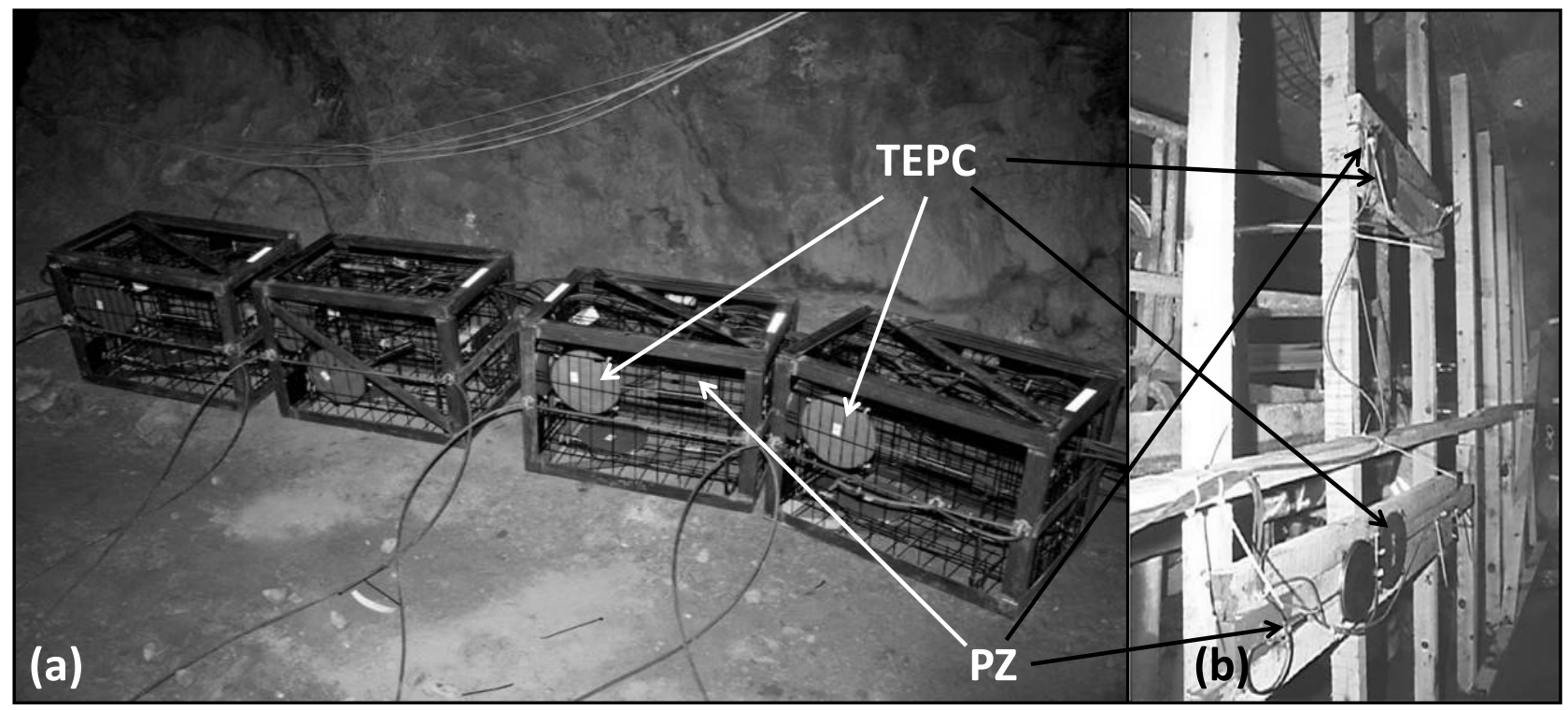

Figure 7 Stope instrumentation for (a) wire cages; and (b) barricades

\subsection{Case study 1}

Figure 8 shows a photograph of the in-stope instrumentation cages and two projections of the CMS surface of the case study stope. The grey squares within this surface represent the location of the two instrumentation cages. One cage (C1) was installed close to the brow while the other (C2) was installed below the main body of the stope. Two TEPC/PZ clusters were installed on the barricade, one at approximately $1.5 \mathrm{~m}$ elevation and the other at approximately $3 \mathrm{~m}$ elevation. The stope was narrow and dipped at an angle of around $65^{\circ}$. It also had a relatively complex undercut access drift. The stope was filled entirely with one type of paste.

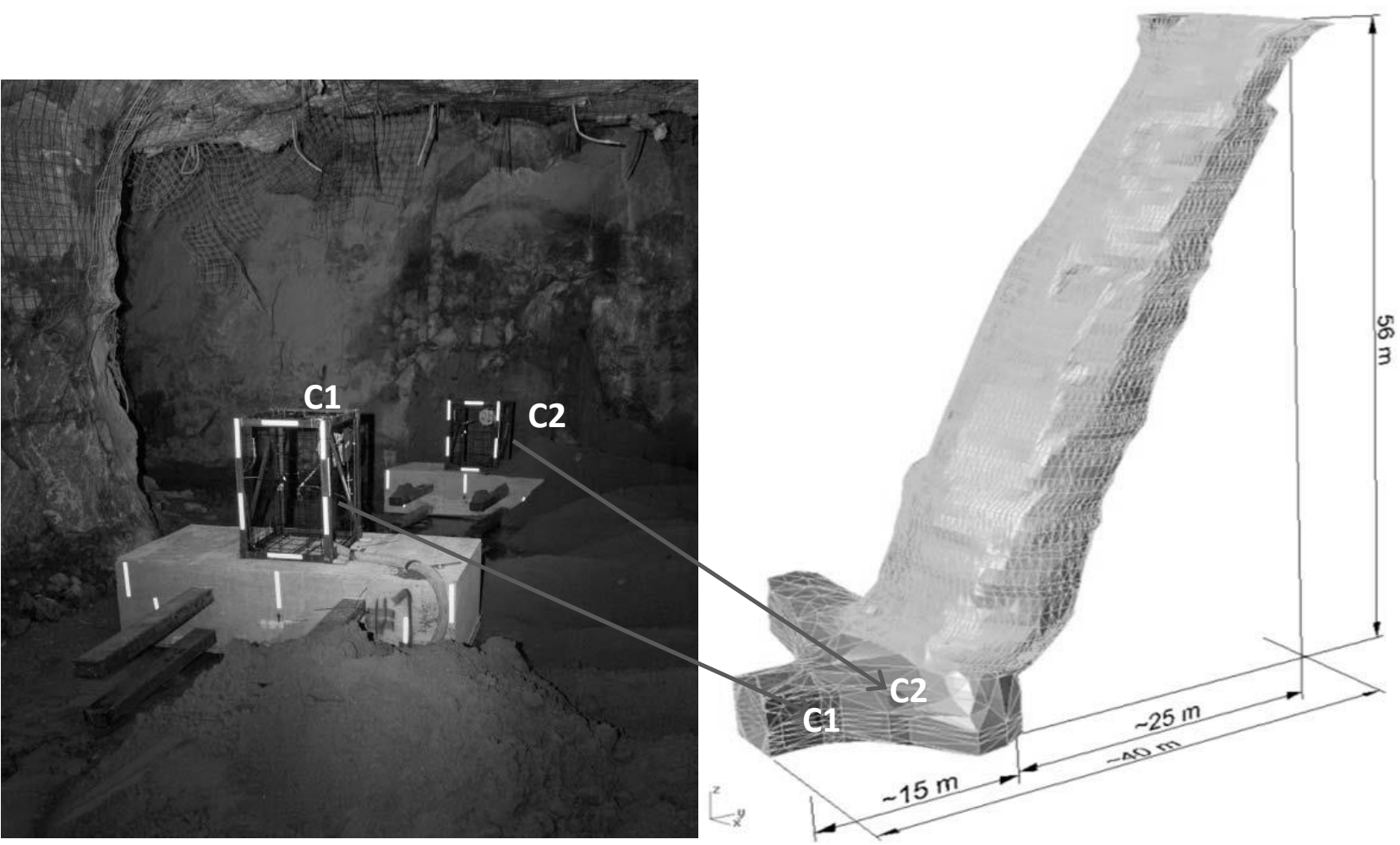

Figure 8 Case study 1 stope instrumentation and CMS surface with dimensions 
Figure 9 compares the results between the $\mathrm{C} 1$ and $\mathrm{C} 2$ model locations and the $\mathrm{C} 1$ and $\mathrm{C} 2$ stope instrumentation. The dashed lines show the model result while the solid lines show the instrumentation results. Black lines show the vertical stresses (Z), grey lines show the $\mathrm{X}$-direction horizontal stresses $(\mathrm{X})$, light grey lines the $y$-direction horizontal stresses $(\mathrm{Y})$, and hollow black lines the pore water pressure (PP).

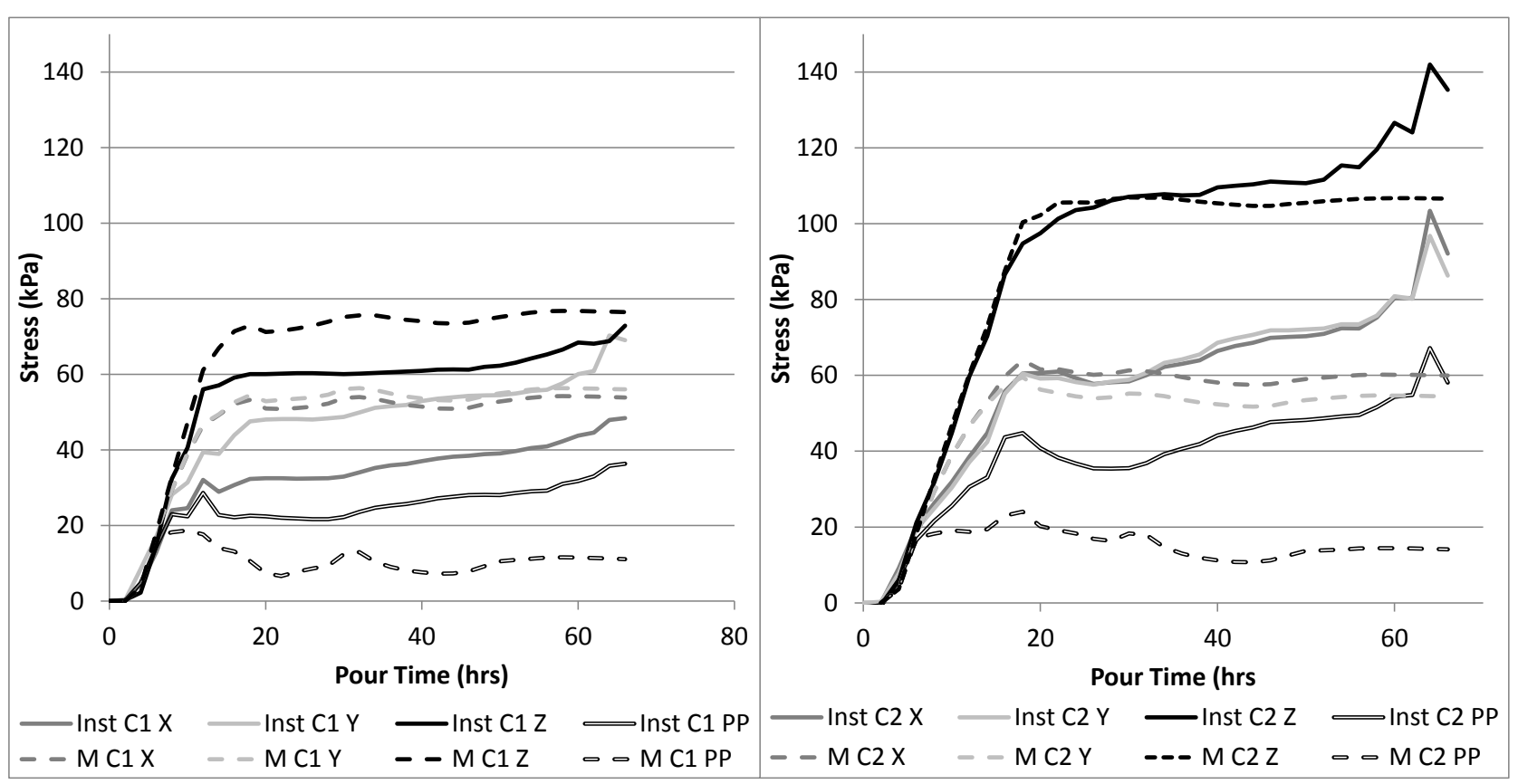

Figure 9 Model and instrumentation results for the $C_{1}$ and $C_{2}$ locations

These plots show that the model was able to match the general trends shown in the instrumentation. In particular, the vertical and horizontal stresses are generally within $10 \mathrm{kPa}$ of each other. The modelled PP curves are lower than the field results. However, all of the instrumentation show a general rise with time which the model does not replicate.

Figure 10 compares the instrumentation and model results for the barricade location. Again, the stress curves are fairly close but the PP curves are not. This is probably due to close vicinity of the PP $=0$ boundary condition.

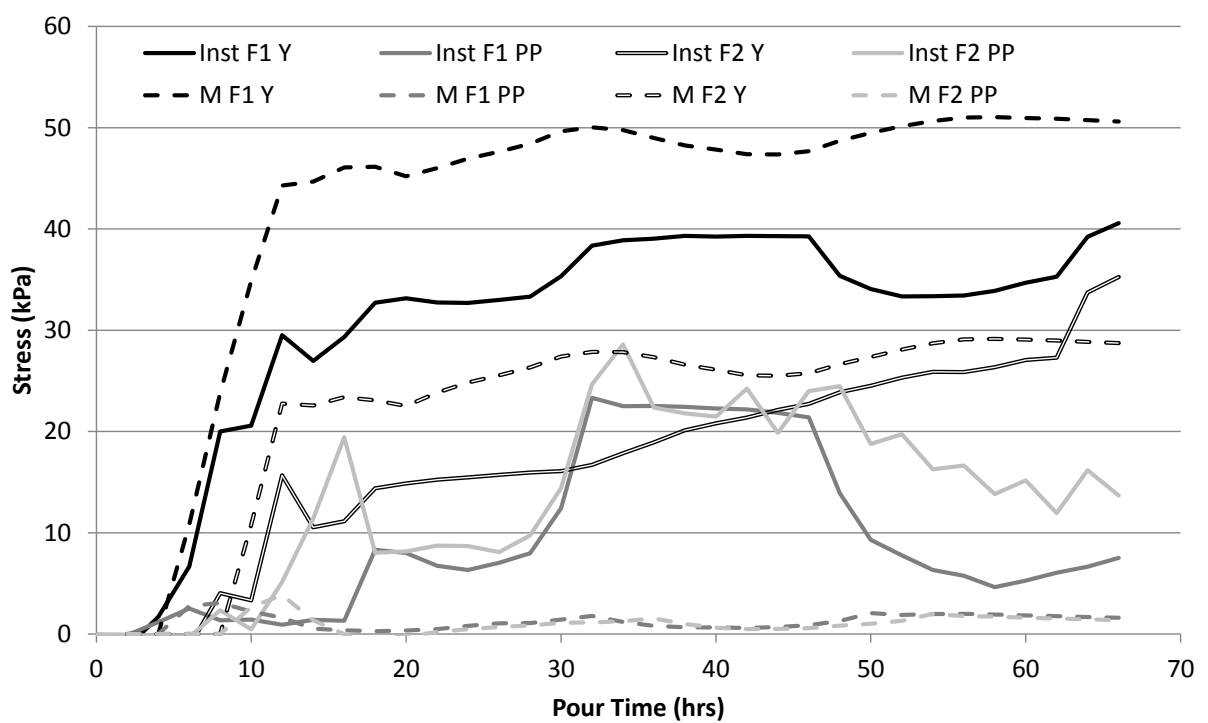

Figure 10 Model and instrumentation results for the barricade instrumentation 
One of the benefits of modelling is that it can be used to link together the discrete measurement locations to present a 'big-picture' of what is happening in the stope. Figure 11 shows a series of contour plots taken from along a cross-section of the model geometry, approximately bisecting the access drift in half. The contours shown are for Z, PP, and Z'. The contour results are shown at 8, 16, 24, 32, 52 , and 66 (end of pour) hour.

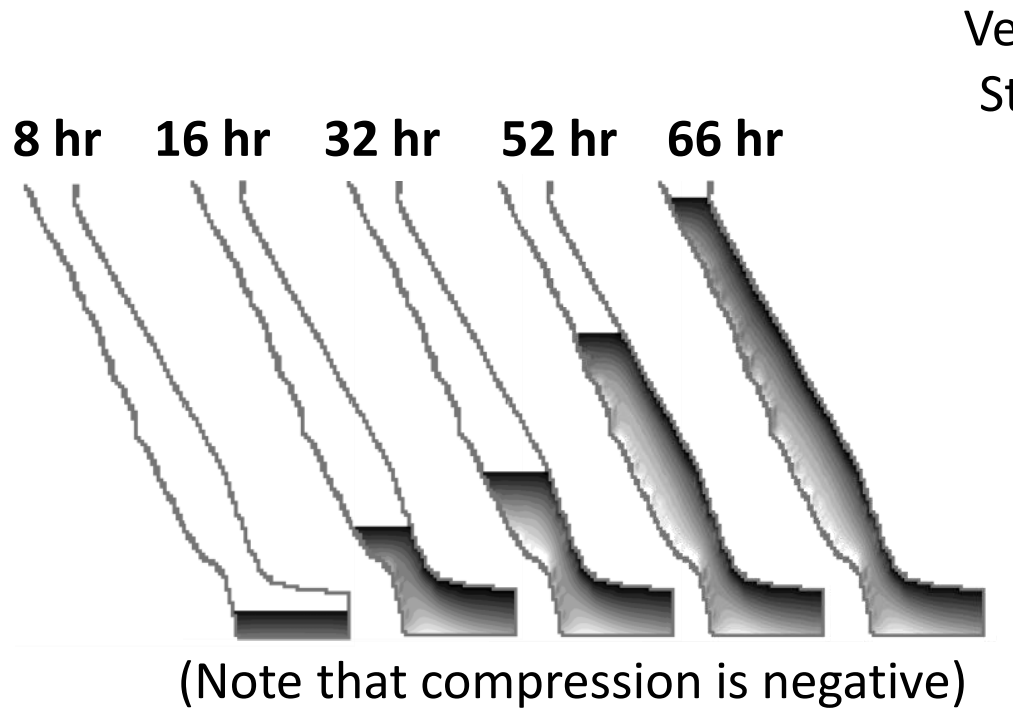

Vertical Total

Stress (kPa)

$-1.4000 \mathrm{E}+05$

$-1.3000 \mathrm{E}+05$

$-1.2000 \mathrm{E}+05$

$-1.1000 \mathrm{E}+05$

$-1.0000 \mathrm{E}+05$

$-9.0000 \mathrm{E}+04$

$-8.0000 \mathrm{E}+04$

$-7.0000 \mathrm{E}+04$

$-6.0000 \mathrm{E}+04$

$-5.0000 \mathrm{E}+04$

$-4.0000 \mathrm{E}+04$

$-3.0000 \mathrm{E}+04$

$-2.0000 \mathrm{E}+04$

$-1.0000 \mathrm{E}+04$

$0.0000 \mathrm{E}+00$

$4.0000 \mathrm{E}+03$

(Note that compression is negative)

Pore Water

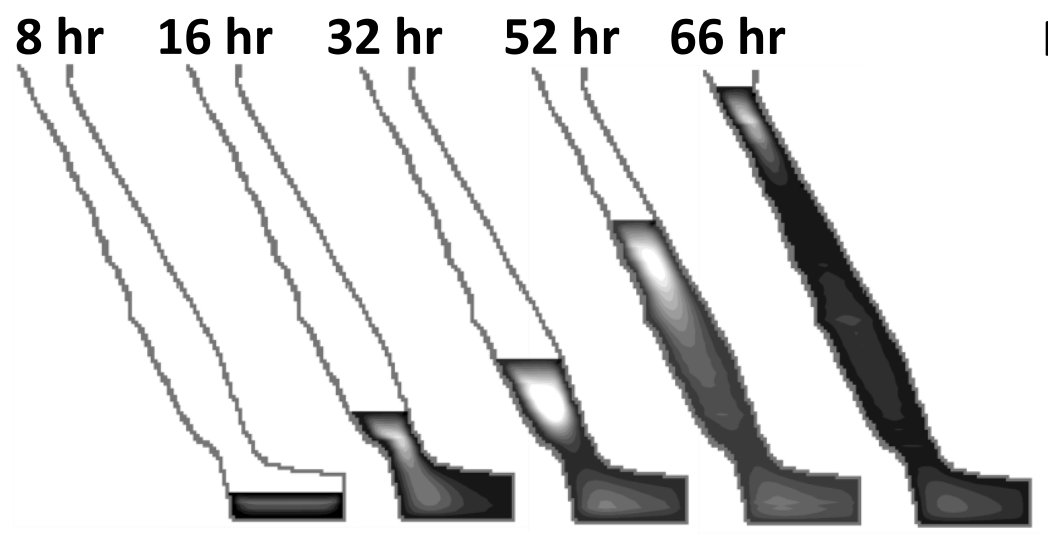

Pressure $(\mathrm{Pa})$

Vertical Effective

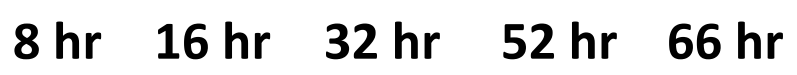

Stress ( $\mathrm{kPa})$

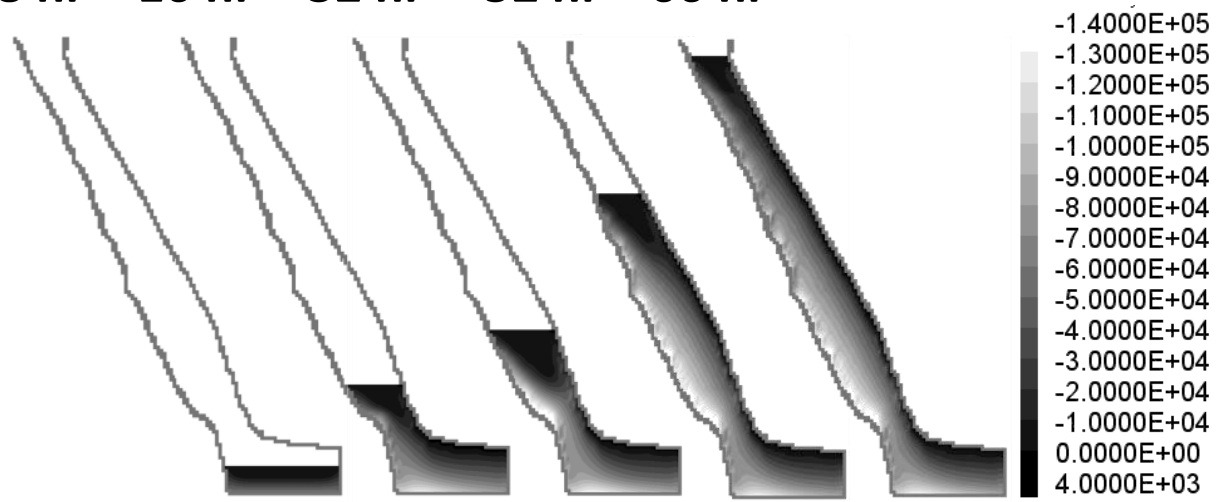

(Note that compression is negative)

Figure 11 Contour plots of vertical stress, pore water pressure, effective vertical stress, and specific discharge 
Both the $Z^{\prime}$ and $Z$ contours are similar trends except the top $5 \mathrm{~m}$ of the CPB column. In this zone the $\mathrm{Z}$ stress shows isotropic behavior and the $Z^{\prime}$, understandably, shows the same zones with no effective stress. This is apparent at every age of contour plot. It is also interesting to observe that the higher stresses are shown on the footwall side due to the inclination of the stope. Attention should be drawn to the small 'step' between the undercut and the main body of stope. This narrowing seems to shield the lower portions of the stope as exhibited by very little change in $Z$ as the rest of the stope fills.

The PWP plots shows the generation of a high PP bulb in the centre of the paste mass only when the undercut is filled. However, after the CPB starts to enter the main body of the stope, the high PP bulb starts to migrate up the stope, following the rise of paste. The model indicates that there is very little change in the PPs in the drift once this bulb has moved into the main body of the stope.

The specific discharge plots also show the migration of the high drainage area from the floor of the stope to the sides of the drift, and then up the walls of the stope body.

\subsection{Case study 2}

The second case study stope is a highly irregular shaped stope. Figure 12 shows a photograph and a CMS surface plot. The instrumentation clusters are shown as white squares with black borders. This stope is interesting as it has two access drives. Cages were only installed in one drive which is circled in the figure below. Both barricades were instrumented. This stope was also different as it was filled with two different pastes. A higher binder paste filled the bottom $7 \mathrm{~m}$ while the rest of the stope was filled with lower binder paste.

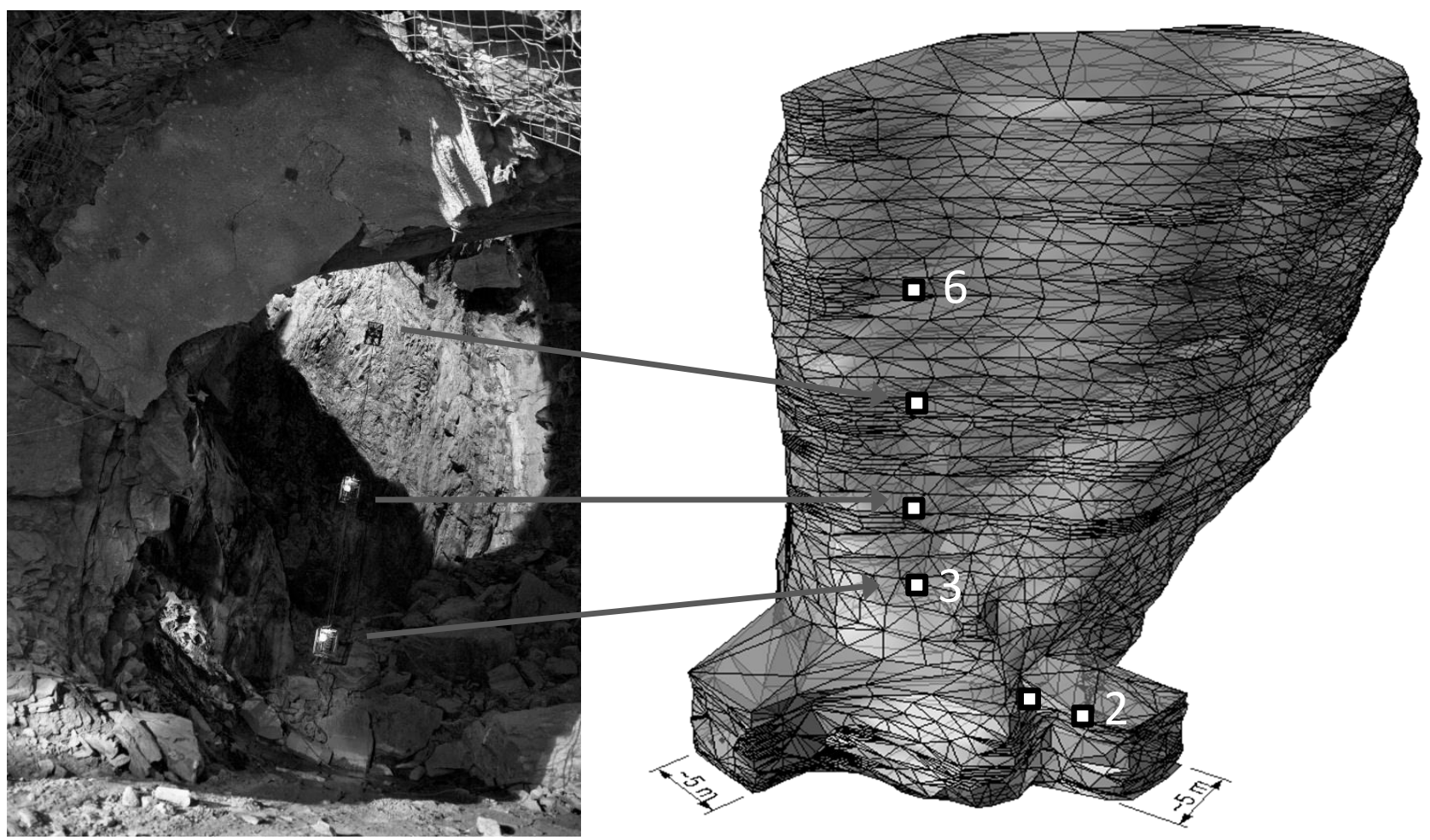

Figure 12 Case study 2 stope instrumentation photograph and CMS surface

Figure 13 shows a comparison of the results from cages 2, 3, and 6. Cage 2 was located with the undercut drive, close to the barricade. Cages 3 and 6 were located in the approximate centre of the stope, with cage 3 being at $\sim 2.5 \mathrm{~m}$ of elevation and cage 6 at $\sim 20 \mathrm{~m}$ of elevation. The results from the other cages are not shown as they had similar results. 

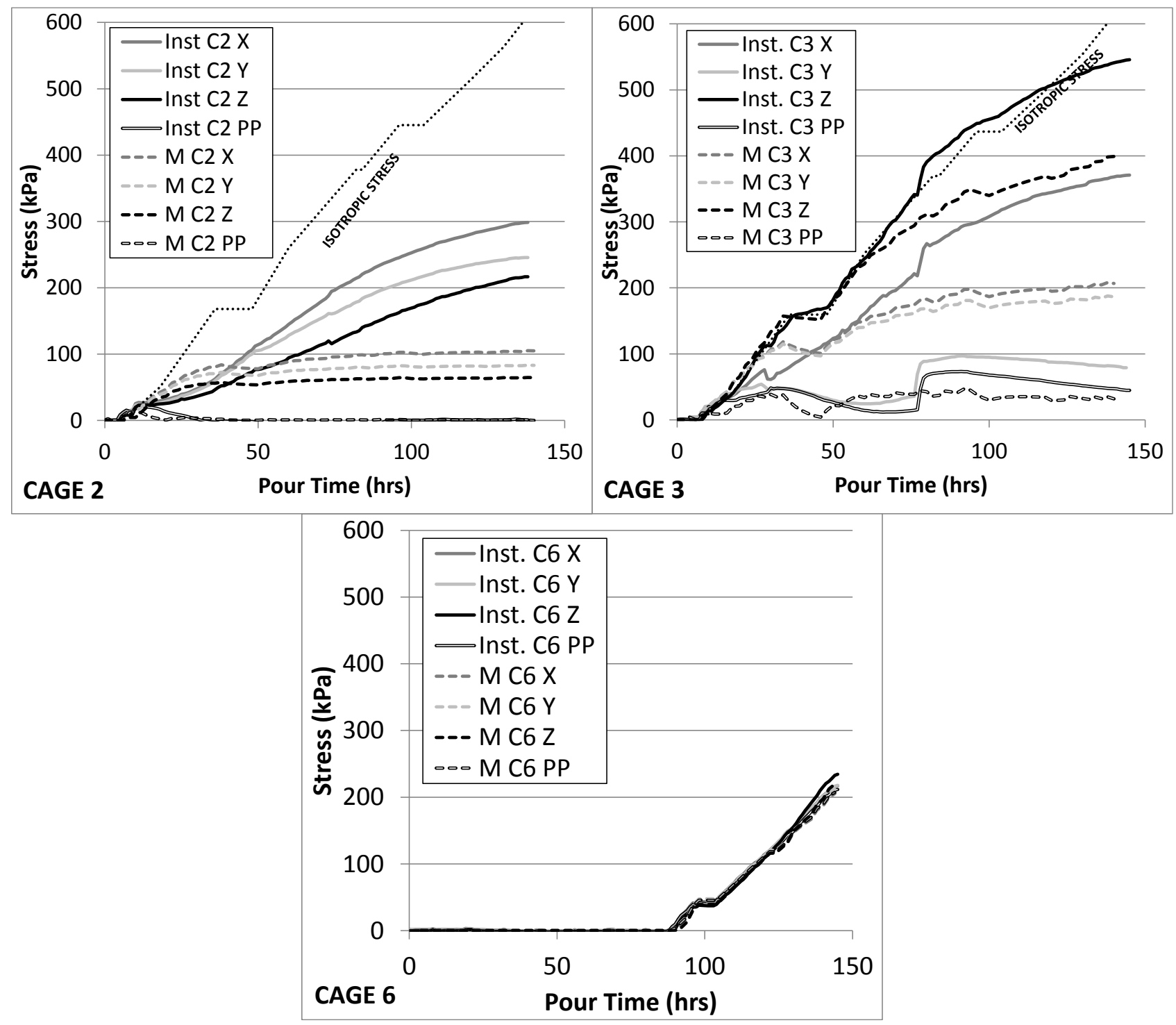

Figure 13 Comparisons of instrumentation and model results for cages 2, 3 and 6

These plots show that there is limited correlation between the cage 2 results, some correlation between the cage 3 plots, and very good correlation between the cage 6 plots. Cages 2 and 3 were encased within the high binder paste while cage 6 was encased in the low binder paste.

The cage 3 graph shows a very interesting trend. There was a plant shutdown between the 38th and 50th hour. Up to this point there had been very good correlation in the results. However, after this point there is a discrepancy as the modelled vertical stress decreases while the instrumentation shows an increase in stress. This increase in stress was unexpected as no paste was entering the stope so no additional material load was placed. Similar trends can be observed in the cage 2 results.

An analysis of the relationship between temperature and in situ stresses for cages 2 and 3 are shown in Figure 14. The gaps in the curves indicate when the plant was down and have been labelled as 'pour stoppages'. It can be observed in both plots that stresses continue to rise with temperature even though the plants were down. 


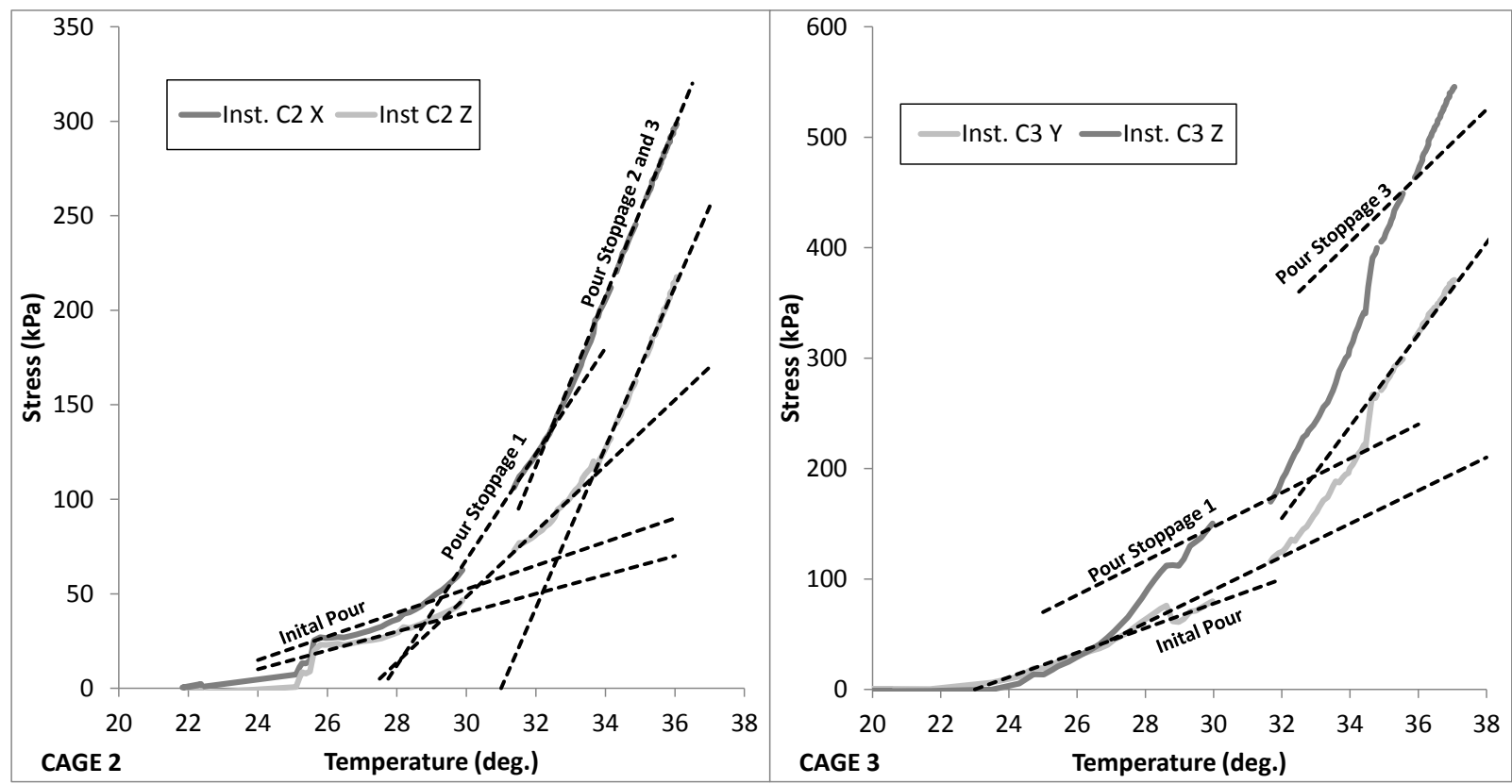

Figure 14 In situ stress versus temperature for cages 2 and 3

The rate of stress change due to temperature increase was calculated by determining the difference between the initial pour rate and the pour stoppage rates, and applied to the model results seen in Figure 13. These modified results are shown in Figure 15 along with the unmodified results. This comparison shows that the thermal correction brought the modelling results much closer to the instrumentation results. As the model does not take into account any sort of thermal behaviour, the fact that the modified and instrumentation curves are close suggests that model was modelling the non-temperature induced stresses correctly. 


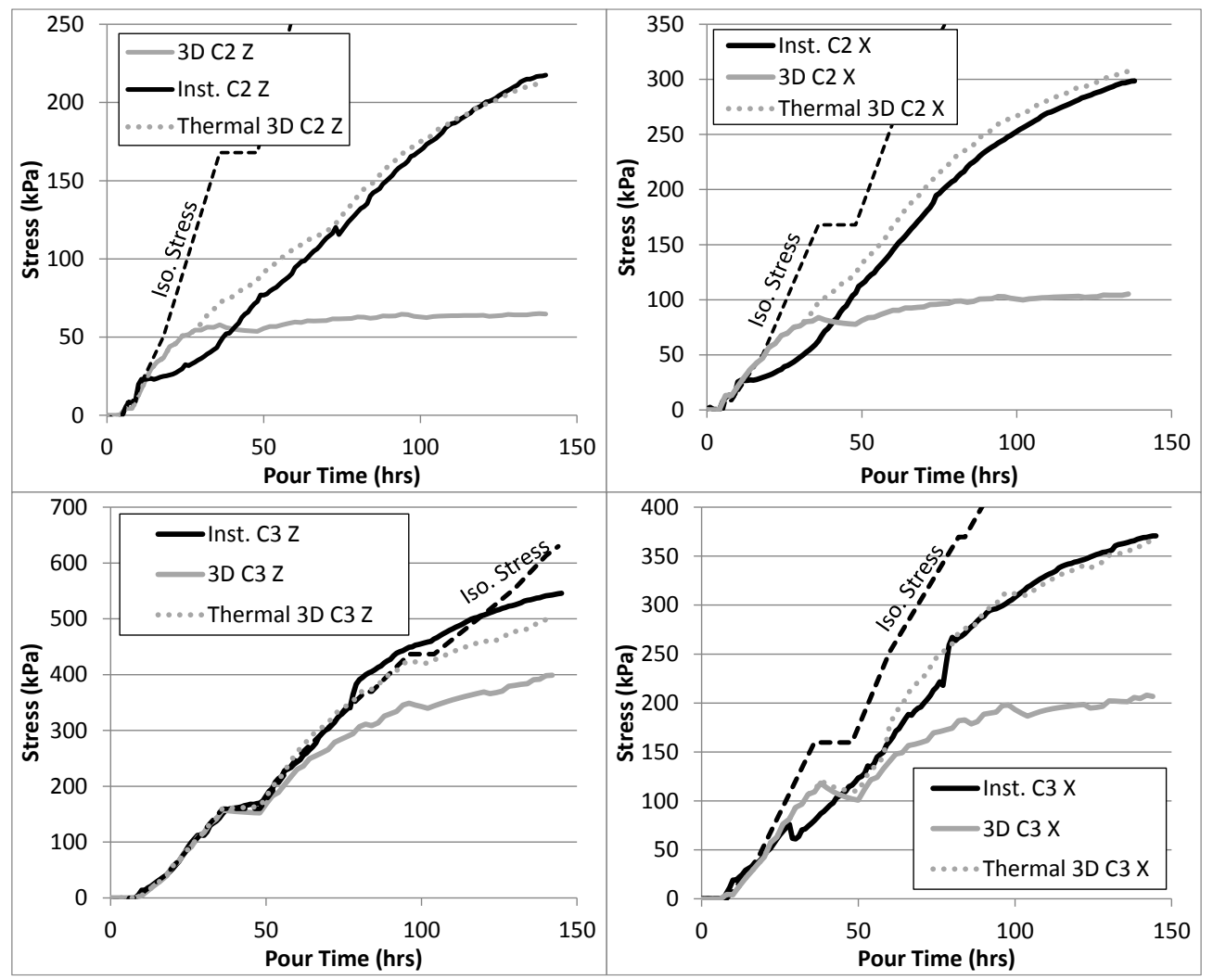

Figure 15 A comparison of instrumentation results with model results that have been modified according to the stress increase due to temperature rates determined from Figure 12

Vertical stress (Z), pore water pressure (PP), and effective stress ( $\left.Z^{\prime}\right)$ contour plots are shown in Figure 16. Note that these contours are shown as a wedge with the wedge axis being along the vertical string of instrument clusters shown in Figure 12. The most interesting thing about these contours is the effect observed due to the change in paste recipe. This change is most apparent in the PP and Z' contours as the lower portion of the stope appear to be protected from the stresses generated by the material above. This indicates that the model is capable of modelling two different materials in the stope and that the higher binder plug is working to protect the barricade. 


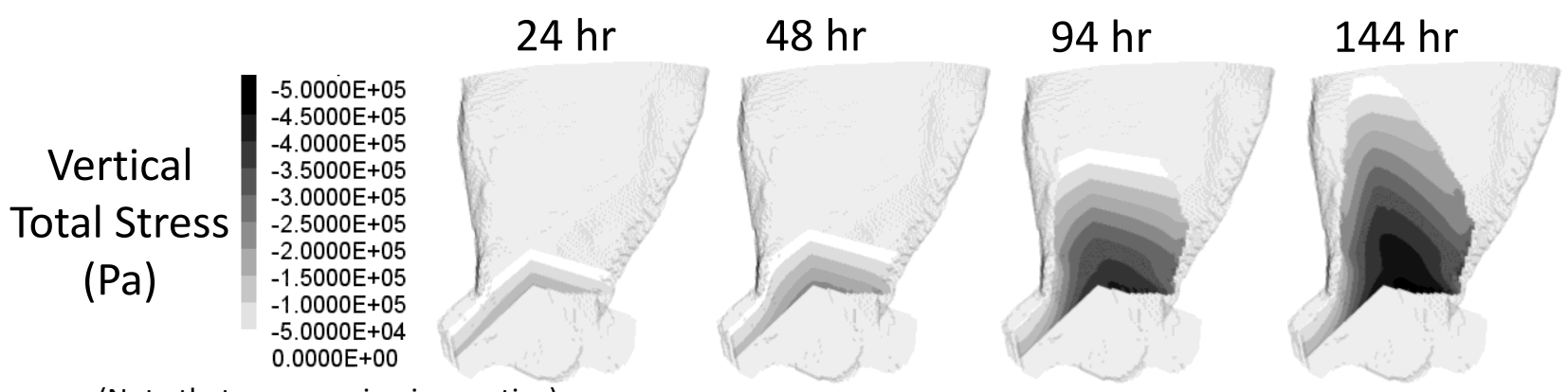

(Note that compression is negative)

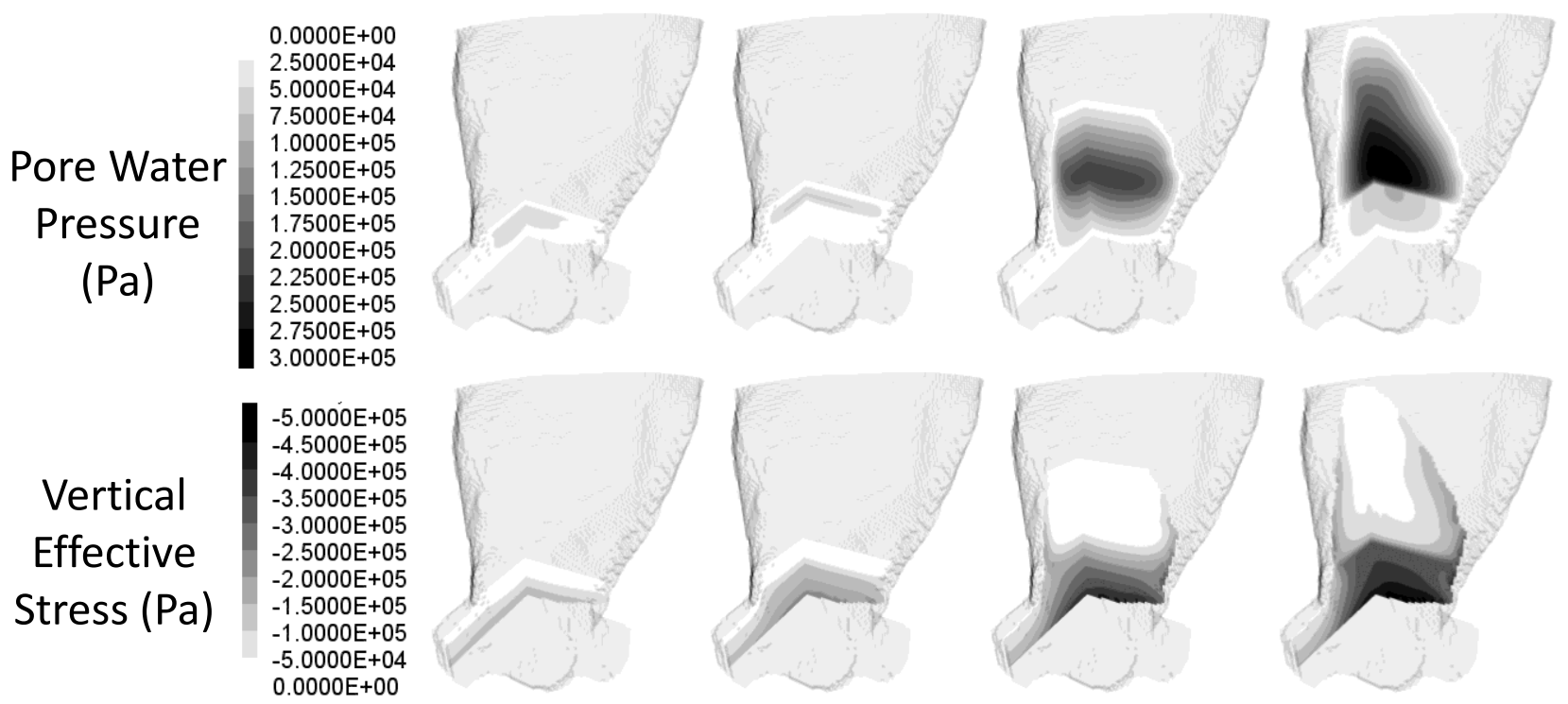

(Note that compression is negative)

Figure 16 Contour plots for the case study 2 stope showing vertical stress, pore water pressure, and effective vertical stress

\section{Conclusions}

This paper has presented a methodology that was used to create a numerical model based in FLAC3D that was designed to model the development of stresses within an underground stope that was backfilled with cemented paste backfill. As part of this methodology, the model design criteria, approach, and input parameters required were discussed. Included in the input parameter discussion was a description of the laboratory methods for determining the input parameters.

The results of two case studies were presented. The case study stopes were different in geometry, paste recipe(s), and fill rates. Despite this, the numerical model was able to, using the stope's geometry, filling strategy (mix designs, fill rates, and possible pour stages), and any pertinent material properties, produce stress results that are similar in both trend and magnitude as results recorded from in situ instrumentation that had been placed in backfilled test stopes.

\section{Acknowledgement}

The authors thank Matt Pierce and Jim Hazzard of Itasca Consulting, summer students Robin Malik and Michelle Moore, and Research Associate Dragana Simon.

Thank you to the Natural Sciences and Engineering Research Council Canada, Barrick Gold Corporation, Inmet Mining Corporation (now First Quantum), and Xstrata (now Glencore Xstrata) for their support of the University of Toronto Geomechanical Design of Cemented Paste Backfill Systems Project. 


\section{References}

Boumiz, A, Vernet, C \& Tenoudjit, FC 1996, 'Mechanical properties of cement pastes and mortars at early ages - evolution with time and degree of hydration', Advanced Cement Based Materials, vol. 3, pp. 94-106.

Galaa, A, Grabinsky, MW \& Bawden, WF 2012, 'Characterizing stiffness development in early age cemented paste backfills with sand in a non-destructive triaxial test', Proceedings of the 65th Canadian Geotechnical Conference.

Itasca Consulting Group, Inc. 2009, 'FLAC3D: Fast Lagrangian Analysis of Continua in 3 Dimensions', Version 4.0, Itasca Consulting Group, Inc., Minneapolis.

Thompson, BD, Grabinsky, MW, Veenstra, RL \& Bawden, WF 2011, 'In situ pressures in cemented paste backfill - a review of fieldwork from three mines', in RJ Jewell \& AB Fourie (eds), Proceedings of the 14th International Seminar on Paste and Thickened Tailings, Australian Centre for Geomechanics, Perth, pp. 491-504. 
